it: in fact it demonstrates the axiom for solids with the exception of a special class of cases. But into these questions I shall not enter further at present.

After I had obtained practically all the results given in this paper, $I$ found that a good deal had been already done by others, though in a somewhat different way. In particular, the general problem of Prop. 3 above is completely solved in a paper by Robert Brodie, published in the T.R.S.E., Vol, XXXVI. part 2, p. 307, entitled "On Professor Kelland's Problem on Superposition," in which he refers to some previous papers by Kelland in earlier volumes. Again, Perigal (Messenger of Mathematics, II. p. 103) gives a solution for the case of Euclid I. 47, which is generalised to some extent by Harry Hart (Messenger, VI. p. 150).

\title{
On the Flementary Differentiations.
}

By R. F. Muirhead, M.A., B.Sc. 